\title{
Narrative Reframing of Stories and Fables: Implications for Counseling
}

\author{
Ida A. Chauvin \\ Latoya A. Pierce \\ Louisiana Tech University \\ Psychology and Behavioral Sciences \\ Ruston, LA 71272, USA \\ Janelle R. McDaniel \\ University of Louisiana Monroe \\ Psychology, Behavioral and Social Sciences \\ 700 University Avenue \\ Monroe, LA 71209, USA
}

\begin{abstract}
Stories and fables play a vital role in many forms of human communication and even the counseling profession. Lives and relationships are shaped by the stories we hear and the meaning we give to the experiences shared. When a story is reframed by a skilled counselor, that narrative can be used as an appropriate tool to expand mind sets, foster empathy, and even guide moral-decision making. This review examines and summarizes the incorporation of storytelling (narrative reframing) and its intrinsic value in therapy and in other places. Included in this article is an overview of using storytelling in both historical and current perspectives. Also discussed are the key concepts of storytelling, sources and benefits, and the goals along with a discussion of the teaching the narrative skill set to counseling studentsforuse across populations.
\end{abstract}

Narrative therapy, primarily developed by Michael White and David Epston and widely practiced by therapists worldwide, involves listening to and telling stories about individuals and their challenges in order to help clients make changes and improve their quality of life (for review, see Epston, 1992; White et al., 1990). Storytelling isan age-old process of presenting a narrative metaphor that makes sense. Stories, tales, metaphors, fables, parables, and folklore have been used as part of therapeutic healing in a number of ways since ancient history in all ages, cultures, and races. It has been integrated into all types of therapy such as group, individual, family and couple therapy and used for clients of all ages (Etchison, \& Kleist, 2000). It has been suggested that human beings are narrative by nature and that many of the lessons learned in life are derived from cognitive moral development (Rusnak, 1985).

The focus of narrative therapy is the collaborative approach between the counselor and client or clients that allows us to construct a story to give our lived experiences meaning. By the same token, we can also deconstruct those stories and change the meaning (Angus \& Greenberg, 2011). We can also tell stories that will be meaningful to clients and help them reframe their thoughts, showing how one object or event can have multiple meanings. Narrative reframing is an interactive approach.

For example, a client approaches the counselor stating that he always wanted to go to college. He attempted and failed at a university twice, community college twice, technical college and trade schools two or three times, and is currently looking at another trade. He feels like a failure. One strategy is reframing his thoughts by asking the client to separate themselves from the problem, trying to see a different perspective. This may reveal some strengths and unrecognized potential in the client. It could be a powerful revelation when the counselor interprets this story in a different way (Ricks, Kitchens, \&Goodrich, 2014), one where a determined individual never gives up. Having an individual see themselves as struggling instead of a failure can be powerful. Telling a story about the struggles of others against insurmountable odds (for example, refugees, victims of national disasters, war and other human plights) may allow clients to draw a parallel to their own story.

Helpful and timely stories are a part of our personal cultural and individual development. Much of our repertoire for storytelling comes from the stories told to us in childhood. Often, storytellers have valuable life experiences they use to draw on for their stories. Aesop, the fable maker of ancient Greece, provided scores of tales with explicit and specific morals which are still passed through generations. 
In the modern technology era, we now learn stories from television, radio, theater, book, billboards, and from the Internet, some of which we will pass on to future generations as it has become a part of our own identity (McQueen \& Hobbs, 2014).

Whereas children view stories as entertainment, paying little attention to implicit or vague morals or metaphors, clinicians find great utility in the practice of telling stories and narrative conversations as it provides an opportunity for clients to examine, reflect, and recognize empowering strengths and skills (McQueen, C., \& Hobbs, C. 2014).American psychiatrist Milton Erickson based much of his work on this idea by literally telling stories to his patients. Bettleheim (1975) utilized metaphors, fairy tales, and fables as a means of therapeutic intervention. When we communicate with other colleagues and peers, we often use self-narrative that enables us to better construe who we are and where we are going (Gudmundsdottir, 1991). This self-narrative can evolve on a cultural level and give cohesion to these shared beliefs. Gudmundsdottir (1991) elaborates:"Stories are a part of a narrative way of knowing that is basic to the ways in which human being understand the world and communicate that understanding to others. Pedagogical content knowledge is a narrative way of knowing, and describe (sic) how narratives serve as a way of explaining that understanding to others (Gudmundsdottir, 1991, p. 4)."

Counselors can capitalize on the value of storytelling as part of a balanced approach to therapy. A good story has utility and can be used repeatedly. Most adults can recall stories from their childhood and the themes associated with them. Hoyt (2000) insists for this reason that stories, whether read or told, are an asset to civilization. He encourages the use of both recipe knowledge, which he calls "encyclopedic knowledge," and a more down-to-earth style of making up the story as one goes along. Some stories have great utility and can be multimodal in use.

An example of such a story is Aesop's The Fox and the Grapes. A hungry fox saw some fine bunches of grapes hanging from a vine that was trained along a high trellis and did his best to reach them by jumping as high as he could into the air. But it was all in vain, for they were just out of reach. So he gave up trying and walked away with an air of dignity and unconcern, remarking "I thought those grapes were ripe, but I see now that they are quite sour." The moral: It is easy to despise what you cannot get. - Aesop's Fable

In the fable above, a hungry fox has convinced himself that the grapes he put so much effort into obtaining were sour after all. At first, he saw them as a means to satisfy his current need. Only after exhausting efforts to obtain the grapes, he blames the grapes, seeing them as the problem. Clients may look to blame or demean others as a means to hide their own shortcomings much like the fox does in the story. Using another version of the same theme, an unemployed man may claim that an available job is not good enough for him, citing poor pay perhaps, while in reality, he may actually be afraid of interviewing for the position for fear of failing to get the job. This thinking is counterproductive and may thwart many job opportunities. The old fable could be used to help this client understand his underlying feelings, address his fears, and reframe his thoughts. Past studies have examined the effectiveness of storytelling as an intervention in vocational rehabilitation work with veterans. If the job interview or job search was likened to a story while the counselor teaches the client a better story, better outcome occurred (Krieshok, Hastings, and Ebberwein 1999).

In addition, storytelling can be used as a non-confrontational way to approach a subject with a client in an effort to encourage them to dig deeper into their own thought patterns or attitudes. Some stories can give encouragement or a gentle lesson in a non-preaching and non-accusing manner. At times a story allows us to see what we do to ourselves and to others. Without blaming, condemning, or complaining, new ways to solve fundamental problems are revealed to the client. Well-timed stories may illuminate a problem in a way that incisively gets to the heart of the matter, eliminating the need for other approaches that may be time-consuming or less effectual.

\section{Stories as a Means of Expanding Mind-Sets}

Because stories influence attitudes, behavior, and cultural change, they can allow the counselor to create a climate which builds unity when diversity exists. Stories can reinforce cultural values and even ethics (Semmler \& Williams, 2000). When counselors and therapists share their stories, they can change a client's worldviews or perspectives to include different ideas and solutions that may not have been previously considered. In all settings, stories can reinforce values and virtues and can fill voids in a client's moral education. Counselors are charged with the responsibility of redirecting, reinforcing, questioning, or affirming a client's reality and reasoning infrastructure. Stories allow the recipient to move away from a current mind-set and see a different solution to similar situation (Harney, 2000) .Mental health professionals can use storytelling in attempts to expand mind-sets and maybe reach even difficult clients, possibly those with whom other traditional methods of delivery have failed. In some cases, the counselor needs to challenge, fine tune, or change these mind-sets that interfere, block, or otherwise prevent healthy relationships and social living. 
It has been argued that a good method for teaching values would be one that introduces morals along with teaching methods of analysis and judgment that produce answers about right and wrong (Sanchez, 1999). Stories can do this implicitly.

Storytelling helps mental health professionals reveal truths to their listeners (Harney, 2000). Harney further states that a story acts as a mirror for clients to reflect back on some other real-life struggle or problem and gain a new prospective. Much of the integrity and moralistic lessons we learn come from literature and the humanities. Even simple stories can impart life lessons which can be analyzed for their implications. Some lessons may be fallacious and thus offer room for critical analysis. English author G.K. Chesterton (1908)illustrated this quite well in his analysis of fairy tales: "If I were describing them in detail I could note many noble and healthy principles that arise from them. There is the chivalrous lesson of 'Jack the Giant Killer;' that giants should be killed because they are gigantic... it is a manly mutiny against pride as such.... There is the lesson of 'Cinderella,' - exaltavithulimes [the uplifting of the humble]. There is the great lesson of 'Beauty and the Beast;' that a thing must be loved before it is lovable. There is the terrible allegory of the 'Sleeping Beauty,' which tells how the human creature was blessed with all birthday gifts, yet cursed with death; and how death also may perhaps be softened to a sleep.... I am concerned with a certain way of looking at life, which was created in me by the fairy tales... (p. 55)"

In the therapeutic setting, clients often focus on emotions and primal instincts rather than reason and critical thinking. Storytelling can be used to challenge single-minded, emotionally driven value systems. For example, despite the high levels of illiteracy in prison, storytelling and analysis of literature is suggested to have the power to change lives, attitudes, and actions in this population (Trounstine,2007). The humanities emphasize values, community building, and cognitive skills, all of which aid in moral decision making. Trounstine further suggests that literature can aid inmates in changing their lives. If one can think through a character's role, they can think themselves through life's problems.

Using the Narrative Metaphor to Externalize Problems

A story can stimulate critical and creative thinking allowing the individual to transfer knowledge about a place, time, or event. To do this, the story must have a theme. The theme of a fable is its moral; a parable, its teaching; a work of fiction, its view of life and behavior. The client can extract the theme from the characters, the action, and the setting that make up the story. It is the duty of the storyteller to make the connection with the client by finding somecommon ground.Counselors knows that preaching and moralizing to clients are not agents for change. Through narrative therapy, which at the foundation is storytelling, counselors and educators can make attempts to examine and use the meanings and consequences that are the foundation of the stories and experiences clients bring to therapy (Semmler\& Williams, 2000). The use of narrative therapy can externalize the moral of the story for the client so that "self-healing resources inherent in the soul can speak to us of its neglected longings and make us whole" (Parry, 1997, p. 120). Telling a story to a client can reveal new and better ways for them to solve problems, see other's views, exchange ideas, and draw parallels to their own current issues. The use of stories and parables has been recommended to help clients in therapy visualize and resolve the major issues between the story and their actual lives (Harney, 2000). Deeply ingrained in our society are the rules and principles by which we live. Thinking about "lived experience" from different perspectives and generating alternative stories can allow the client to behave in different and better ways (White et al., 1990).Wexler (1996) believes that literature contributes to the exercise of the moral imagination. If clients can be made aware of the subtle yet relevant complexities of a situation, in other words, the multidimensionality of a problem, and connect this with the human experience, literature will encourage them to empathize with others and understand their inner selves and their motives and behaviors.

Storytelling as an Educational Tool

Narrative storytelling has long been an important part of educational and psychological research communities (Polkinghorne, 1988; Saebin, 1986). Although there are relatively few scientific findings about the effectiveness of storytelling alone as a means of therapy, it has been shown to be an effective complementary tool for guiding in the classroom. Besides introducing or reinforcing values and virtues, narrative therapy and storytelling can be effectively substituted and used as an alternative way to reveal truths. Most educational professionals use a type of narrative unconsciously without realizing they are doing so. Morton (1996) describes group work using narratives as an approach to educational therapy. In the school setting, storytelling can be a great opportunity for a student to get through emotional difficulties while the teacher skillfully guides the process (Morton, 1996).Play therapists, too, have long been proponents of storytelling as a tool for children to express their conflicts and anxieties. Sharing and creating a common experience aid in the development of the client's ability to interpret events beyond the immediate experience. Through art and stories, children share their perception, reactions, and stressors in a safe and supportive setting (McNamee \&DeChaiara, 1996). Carlson and Arthur (1999) maintain that the use of stories allows children in therapy to separate themselves from the hurtful experience and deal instead with the theme symbolically. 
Webb (2007) focuses on the treatment of children who have experienced crises resulting from psychological, physical, or environmental events. Because children do not have the coping mechanisms of adults and sometimes lack adequate familial support to deal with such stressful situations, storytelling and other devices of play therapy can be useful methods of dealing with these intense and traumatic events.

Storytelling in Counselor Education

For many counseling graduate students, the crux of their degree program is to begin learning how to utilize counseling skills and interventions. It is the exciting time when students can flex their counseling muscle and begin the application phase of learning. Storytelling can be a powerful skill to put into their counseling toolbox. As most graduate programs have a Techniques or Pre-Practicum course, storytelling can easily be incorporated into the pyramid of micro skills that are introduced to students. There are three ways to accomplish this goal: 1) lecture as an introduction, 2) role plays as practice, and 3) reflection papers or case scenarios to analyze the skill. Lecture is typically the starting point to introduce any new concept to students. The instructor has the capacity to introduce the idea of storytelling, why it is used, and the meaning it could potentially create for the client. The easiest way to provide an example of course is for the instructor to tell a story and process it with the class as a whole. This mode of teaching storytelling has the potential to do two things. First, it will give individual students an opportunity to discuss their personal meaning from the story. If a climate of safety has already been established, students may feel empowered by sharing their interpretation of the story. Empowerment is typically a client goal and a basic tenet of counseling in general. Secondly, it allows each student to observe and vicariously learn how their interpretation of the story is similar or different from others. This occurrence helps to broaden the students' perspective which is also a goal for counselors in training as it relates to cultural competence and the ability to work with a diverse group of clients.

Role plays are always a popular vehicle for engaging in new counseling skills as they afford the students the opportunity to practice what they have learned. Once students are taught how to do storytelling, the best way to practice it is to incorporate it into a role play. The instructor may initially provide a "staged" example or model of how to utilize storytelling in a role play so students can clearly see how to bridge the skill from simply being a principle to applying it in the context of a mock session. Once students have seen storytelling utilized, they may become more aware of the opportunities to use it in their own role plays with each other. As a technique, storytelling can also enhance the dynamic between counselor and client. For counselors, storytelling keeps the therapist in the "facilitator" role instead of the "advice giving" role. As a general rule, counselors use advice-giving sparingly as it has the capacity to foster client dependence or hinder the relationship if the advice is not successful. It is a much better guideline to help the client generate their own solutions and for the counselor to simply facilitate the process. Storytelling allows the counselor to provide a different perspective to the client without simply giving advice. It provides a creative way to give the client a new lens or outlook on their circumstances and eventually propel them towards change. This concept can be a part of discussion or process time in the techniques or pre-practicum course.

Lastly, storytelling can be incorporated into reflection papers or exams. Like any other counseling skill, students must be given the opportunity to reflect upon their experience using the skill and what meaning it creates. Essentially, students must be able to analyze when it is most appropriate to use the skill, how to use it, and how to help the client create symbolism from storytelling. Reflection papers are a widely used approach to help students formulate their thoughts, feelings, and opinions about the concept. A case scenario is another way to help students analyze the use of storytelling and could be utilized in two different ways. First, the instructor could provide a client profile/scenario and the story that the counselor would utilize. The student can then discuss how the story might be helpful to the client. The other option (which might be considered more advanced) could be for the instructor to provide a client profile and simply ask the student to generate a story that might be helpful to this client. It is important to note that the student should have a plethora of story examples to choose from before attempting option two. The latter option may be utilized for a final exam or for students who have developmentally demonstrated the capacity to conceptualize a clear understanding of storytelling first. To review, storytelling can be incorporated into a techniques or pre-practicum course in a number of ways. Lecture, role plays, and reflection papers/case scenarios are simply a few mechanisms to get students comfortable with this microskill. As students continue to practice storytelling, it will become second nature to them and they will eventually find those moments in which it can be very useful to the client.

\section{Limitations}

Storytelling and narrative therapy, despite all of the positive attributes, do have some criticisms. For example, sometimes clients or students cannot make the proper connection, leaving the counselor or educator to offer their own explanation as opposed to the client or student coming up with their own. If narrative is subject to different interpretations, such as cultural, interpersonal, linguistic, and cognitive variables, as Kelly (1999) suggests, how can we truly judge that a person correctly decodes the information? 
It is worth mentioning that in utilizing narratives, the counselor must consider the story, the storytelling, and the cognitive level of the listener. Most proponents will agree that if there is a breakdown of any of these parts, then the resulting interpretation is less meaningful. This highlights the need for the counselor to be aware of their role in assisting in the process by expanding on the information.

\section{Conclusion}

Whether counselors reframe the client story or share their stories, they can change clients' worldviews or perspectives to include options and ideas never considered in the past. Stories reveal traits to clients that may be previously unknown. Like teaching history and literature through narratives and storytelling, we can build better and stronger relationships with one another, regardless of cultural background. In a global sense, we can strengthen communities and promote healing and healthy relationships. In any event, the issue of promoting moral development, character development, and ethics through communication training still remains fertile ground for further investigation. The strength in the message of a narrative lies with the story, the presentation, and its application. The opportunities for incorporating stories with other theories beyond the ones presented here are limited only by the creativity of the therapist.

\section{References}

Angus, L. E., \& Greenberg, L. S. (2011). Working with narrative in emotion-focused therapy: Changing stories, healing lives. Washington, DC, US: American Psychological Association. http://dx.doi.org/10.1037/12325-000

Bettelheim, B. (1975). The uses of enchantment: The meaning and importance of fairy tales. New York: Knopf.Carlson, R. \& Arthur, N. (1999). Play therapy and the therapeutic use of story. Canadian Journal of Counseling, 33(3), p. 212-226.

Chesterton, G. K. (1908). Orthodoxy. New York.

Epston, D. (1992). Experience, contradiction, narrative \& imagination: selected papers of David Epston\& Michael White, 1989-1991. Adelaide: Dulwich Centre Publications.

Etchison, M., \& Kleist, D. M. (2000). Review of narrative therapy: Research and utility. The Family Journal, 8(1), 6166.

Gudmundsdottir, S. (1991). Story- maker, story- teller: narrative structures in curriculum. J. Curriculum Studies, 23(3), 207-218

Harney, K. (2000). Visualizing psychological concepts in stories, parables, and riddles. Counseling and Values, 44(3), p. $222-227$

Hoyt, M. (2000). Some Stories are Better than Others: Doing What Works in Brief Therapy and Managed Care. Philadelphia, PA: Brunner/Mazel, Inc.

Kelly, T. (1999). Towards a "Common Sense" Deconstruction in Narrative Therapy. Unpublished manuscript.

Krieshok, T., Hastings, S., Ebberwein, C., Wettersten, K., \& Owen, A., (1999). Telling a good story: using narratives in vocational rehabilitation with veterans. Career Development Quarterly, 47(3), p. 204-214.

McNamee,A. S.,\&De Chiara, E. (1996). Inviting StoriesTo Help Young Children Cope with Stressful Life Experiences.

McQueen, C., \& Hobbs, C. (2014). Working with parents: Using narrative therapy to work towards genuine partnership. Educational And Child Psychology, 31(4), 9-17.

Morton, G. (1996). The Therapeutic Potential of Storymaking With Children. Educational Therapy and Therapeutic Teaching, 5-17.

Parry, A. (1997). Why we tell stories: The narrative construction of reality. Transactional Analysis Journal, 27, p. 118-127.

Polkinghorne, D. E. (1988). Narrative knowing and the human sciences. Suny Press.

Ricks, L., Kitchens, S., Goodrich, T. My story: The use of narrative therapy in individual and groupcounseling. Journal of Creativity in Counseling, Mar 2014.https://doi.org/10.1080/15401383.2013.870947

Rusnak, T. (1985). Are Morals Caught or Taught? Education Research Quarterly, 9, p. 37-42.

Sarbin, T. R. (1986). Narrative psychology: The storied nature of human conduct. Praeger Publishers/Greenwood Publishing Group.

Sanchez, T. R. (1998). Using stories about heroes to teach values. ERIC Clearinghouse for Social Studies/Social Science Education.Semmler, P. \& Williams, C. (2000). Narrative therapy: A storied context for multicultural counseling. Journal of Multicultural Counseling and Development, 28,(1), p. 51-62.

Trounstine, J. (2007). Texts as teachers: Shakespeare behind bars and changing lives through literature. New Directions for Adult and Continuing Education, 2007(116), 65-77.

Webb, N. B. E. (2007). Play therapy with children in crisis: Individual, group, and family treatment. Guilford Press.

White, M., White, M. K., Wijaya, M., \&Epston, D. (1990). Narrative means to therapeutic ends. WW Norton \& Company. 